Original Papers

\title{
Raman Microspectroscopy/Imaging Study on Phase-Vanishing Processes of Fluorous Biphase Systems in Microchannel- Microheater Chips
}

\author{
Takeshi AraKI, ${ }^{*}$ Kousei Ueno, ${ }^{* *}$ Hiroaki Misawa, ${ }^{* *}$ and Noboru KitamUra*† \\ *Division of Chemistry, Graduate School of Science, Hokkaido University, Sapporo 060-0810, Japan \\ **Research Institute for Electronic Science, Hokkaido University, Sapporo 001-0021, Japan
}

\begin{abstract}
Temperature-dependent phase-vanishing processes between perfluorohexane (FC-72) and $n$-heptane $\left(\mathrm{C}_{7} \mathrm{H}_{16}\right.$, volume ratio of 1:1 and phase-vanishing temperature $>41^{\circ} \mathrm{C}$ ), were studied in a glass microchannel-microheater chip under solutionflow conditions. Without applying a voltage to the heater at $21^{\circ} \mathrm{C}$, the two liquids in the microchannel were separated into two streams at a solution flow rate $(v)$ of $0.975 \mathrm{~cm} / \mathrm{s}$, while the phase boundary between $\mathrm{FC}-72$ and $\mathrm{C}_{7} \mathrm{H}_{16}$ vanished in the downstream side of the heater at $V=4.5 \mathrm{~V}$. Then, we conducted Raman intensity imaging during the phase vanishing processes in the microchannel by monitoring the band at 756 (FC-72) or $1456 \mathrm{~cm}^{-1}\left(\mathrm{C}_{7} \mathrm{H}_{16}\right)$. At $V=4.5 \mathrm{~V}$ and $v=0.975$ $\mathrm{cm} / \mathrm{s}$, although no phase boundary between the two liquids in the microchannel was observed, the relevant Raman intensity images indicated the inhomogeneous nature of the solution, and distribution of $\mathrm{C}_{7} \mathrm{H}_{16}$ to the $\mathrm{FC}-72$ phase along with solution flow was observed.
\end{abstract}

(Received June 1, 2006; Accepted July 31, 2006)

\section{Introduction}

Phase mixing/separation of a binary/ternary solution system or aqueous polymer solution has been employed frequently in analytical sciences. As an example, Saitoh et al. reported simultaneous extraction and concentration of a hydrophobic analyte (i.e., porphine derivatives and metal chelates) on the basis of temperature $(T)$-induced phase separation of an aqueous poly( $N$-isopropylacrylamide) solution. ${ }^{1-3}$ We also reported recently that laser-induced photo-thermal phase separation of an aqueous triethylamine (TEA) solution and simultaneous single TEA droplet formation in the aqueous solution could be applied to water-to-droplet extraction/concentration of $p$-chlorophenol. ${ }^{4}$

As a new class of phase mixing/separation systems, on the other hand, "fluorous" biphase systems have been developed in the past decade..$^{5-9}$ Highly fluorinated-alkanes, -ethers, and -tertiary amines are called "fluorous" solvents. ${ }^{10}$ A "fluorous" solvent commonly exhibits a $T$-dependent solubility with a nonpolar non-fluorous organic solvent. As a typical example, perfluoromethylcyclohexane and toluene are separated into two phases at room temperature, while the two liquids become miscible above a critical temperature: $T_{\mathrm{c}}$ (phase-vanishing temperature), $89^{\circ} \mathrm{C} .{ }^{11}$ Furthermore, although an ordinary organic compound shows a low solubility in a fluorous solvent, the compound having a perfluoroalkyl chain(s) is soluble in a fluorous solvent because of "like-dissolves-like" effects and, such a compound has been used as a fluorous catalyst or reagent. On the basis of such physical properties of a fluorous solvent or compound, fluorous biphase/triphase reaction systems have been developed. In the case of a fluorous/organic

$\dagger$ To whom correspondence should be addressed.

E-mail: kitamura@sci.hokudai.ac.jp solvent system containing a fluorous catalyst, for example, the reaction mixture is homogeneous during a thermal reaction above $T_{\mathrm{c}}$, while, after completion of the reaction, it can be separated into two phases by cooling to room temperature. Therefore, this makes it possible to separate a product(s) and the catalyst into the organic and fluorous phases very easily. Such a system is also advantageous as green chemistry, since a poisonous and expensive fluorinated compound can be recovered easily and used repeatedly. In practice, fluorous biphase chemistry in bulk systems has been advanced in the field of synthetic organic chemistry as an extraction-free reaction system. Nonetheless, although a fluorous biphase system relies essentially on the phase mixing/separation phenomena, its physical chemistry is still controversial. Furthermore, if phase mixing/separation behaviors in a fluorous biphase system can be controlled arbitrary, fluorous-based analytical and synthetic chemistry would advance further.

In order to study the physical chemistry of a fluorous biphase system and to manipulate its phase mixing/separation processes, one can employ a microchannel chip. It is now widely recognized that chemical reaction, separation, and/or detection systems can be integrated on a single microchip and that various chemical operations can be conducted along solution-flow in a microchannel. ${ }^{12-23}$ A microchannel-microheater chip has been also reported. In a minute space such as in a microchannel integrated with a heater, local cooling/heating proceeds very quickly owing to large surface area/volume ratios of both microheater and michrochannel. Such characteristics can be applied to various systems. As an example, we reported that thermal phase separation of an aqueous $\operatorname{poly}(N$-isopropylacrylamide) solution could be controlled arbitrary and quickly by an applied voltage to a microheater integrated in a microchannel chip. ${ }^{24}$ We suppose that an idea analogous to that mentioned above could be applied to manipulating $T$-dependent 


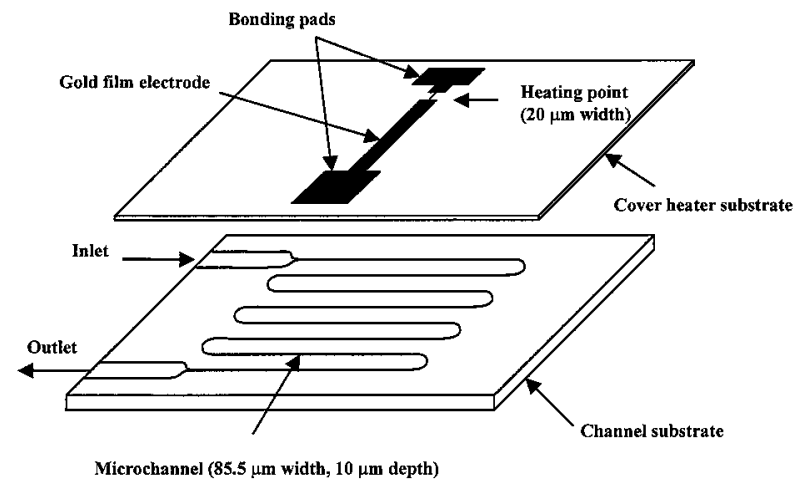

Fig. 1 Structures of a glass microchannel-microheater chip.

phase mixing/separation of a fluorous biphase system in a microchannel-microheater chip. Furthermore, since solutionmixing processes can be observed steadily in a microchannel chip, ${ }^{15,16,21}$ simultaneous spectroscopic observation of the phenomena could provide information about the phase-mixing processes.

As the first approach to test such a research idea, we explored Raman microspectroscopy and Raman intensity imaging of the phase-vanishing processes of a fluorous biphase system in a microchannel-microheater chip. As a fluorous biphase system, we selected a perfluorohexane (FC-72) $/ n$-heptane $\left(\mathrm{C}_{7} \mathrm{H}_{16}\right)$ system, since the system showed a moderate $T_{\mathrm{c}}: 41^{\circ} \mathrm{C}$. In order to pursue such a study, furthermore, we fabricated glass microchannel-microheater chips. In this paper, we report fabrication of glass microchannel-microheater chips and their application to in situ Raman observation of the phase vanishing processes of an $\mathrm{FC}-72 / \mathrm{C}_{7} \mathrm{H}_{16}$ system.

\section{Experimental}

\section{Chemicals}

n-Heptane $\left(\mathrm{C}_{7} \mathrm{H}_{16}\right.$, Wako Pure Chemical Industries Ltd., 99\%) and perfluorohexane (3M Fluorinert ${ }^{\mathrm{TM}}$ FC-72, Sumitomo $3 \mathrm{M}$ Ltd.) were used without further purification. Acetone, methanol, and other chemicals, including diammonium cerium(IV) nitrate, purchased from Wako Pure Chemical Industries Ltd., were used as supplied.

\section{Fabrication of glass microchannel-microheater chip}

The structure of the microchannel-microheater chip used in the present study is shown schematically in Fig. 1. A glass microchannel substrate (Matsunami Glass Ind. Ltd., $24 \times 24$ $\mathrm{mm}$, thickness of $0.45-0.60 \mathrm{~mm}$ ) was cleaned successively by sonication in acetone, methanol, and water ( 3 min each). After drying under a nitrogen gas stream, a chromium layer (thickness $\sim 300 \mathrm{~nm}$ ) was sputtered onto the substrate by a magnetron sputtering system (ULVAC Inc., Model MPS-4000). A photoresist (Tokyo Ohka Kogyo Co. Ltd., OFPR-5000) was spin-coated on the substrate at $500 \mathrm{rpm}$ for $5 \mathrm{~s}$ and at $4000 \mathrm{rpm}$ for $30 \mathrm{~s}$; the substrate was prebaked at $110^{\circ} \mathrm{C}$ for $90 \mathrm{~s}$ to prevent peeling of the photoresist layer during development. By using a mask-aligner (MIKASA Co. Ltd., MA-20), we then exposed the substrate to a $500 \mathrm{~W}$ mercury lamp for $10 \mathrm{~s}$ through a photomask for the microchannel structure in Fig. 1. After the photoresist layer was developed (Tokyo Ohka Kogyo Co. Ltd., NMD-3) and rinsed with pure water, the exposed chromium layer on the substrate was etched in an aqueous $\mathrm{Ce}\left(\mathrm{NH}_{4}\right)_{2}\left(\mathrm{NO}_{3}\right)_{6}$

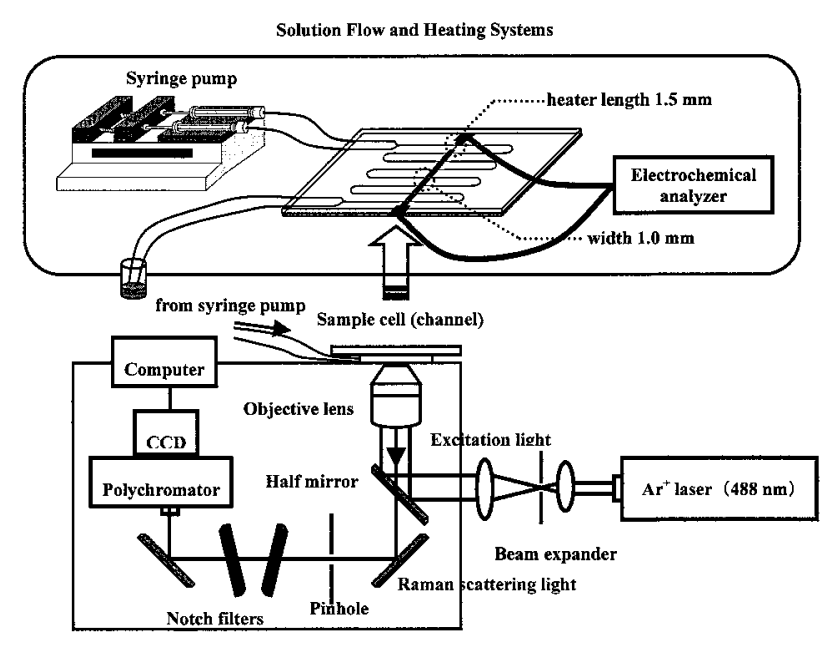

Confocal Optical Microscope

Fig. 2 Experimental setup for Raman microspectroscopy/imaging of a solution flow in a microchannel-microheater chip.

solution (12 wt $\%)$ at room temperature. The exposed glass surface was then etched in an aqueous HF solution $(33-40 \%)$ for $100 \mathrm{~s}$ to fabricate the microchannel with the depth and width of 10 and $85.5 \mu \mathrm{m}$, respectively. Inlet channels to accommodate microcapillaries for tubing with a syringe pump were fabricated by etching the substrate in an aqueous HF solution for a further $30 \mathrm{~min}$.

On the other hand, a microheater substrate (Matsunami Glass Ind. Ltd., $24 \times 24 \mathrm{~mm}$, thickness $0.12-0.17 \mathrm{~mm}$ ) was fabricated by the following lift-off technique. A glass substrate was cleaned and coated with a photoresist, similar to the procedures for fabricating the channel substrate mentioned above. The substrate was then exposed to a $500 \mathrm{~W}$ mercury lamp for $10 \mathrm{~s}$ through a photomask for the microheater structure (Fig. 1). After the photoresist layer was developed and rinsed with pure water, chromium $(\sim 2.5 \mathrm{~nm}$, adhesion layer), gold $(70 \mathrm{~nm}$, heater), and chromium ( $\sim 15 \mathrm{~nm}$ coating layer) were sputtered successively onto the substrate by a magnetron sputtering system. The substrate was then immersed in acetone to remove the photoresist/metal layers. The metal pattern left on the substrate was used as a microheater and as the relevant bonding pads. The width and length of the heater were set at $20 \mu \mathrm{m}$ and $1.5 \mathrm{~mm}$, respectively, and the heater was fabricated at $2.5 \mathrm{~mm}$ in the downstream side of the inlet channel junction. Beside the heater part, the width of the metal layer was set at $1 \mathrm{~mm}$ to avoid heat generation and the size of the bonding pad was designed to be $3 \times 3 \mathrm{~mm}$.

Bonding between the channel and heater substrates was made by using an epoxy-based photoresist (NANO ${ }^{\mathrm{TM}}$ SU-8 2002, Microchem Co. Ltd.) as an adhesion layer. First, the channel and heater substrates were cleaned successively by sonication in acetone, methanol, and water ( 3 min each). After the substrates were dried, they were treated in a concentrated sulfuric acid and rinsed with enough pure water. The resist was spin-coated on the back-side of the Au heater substrate at $500 \mathrm{rpm}$ for $5 \mathrm{~s}$ and at $4000 \mathrm{rpm}$ for $30 \mathrm{~s}$. The substrate was pre- and soft-baked at $65^{\circ} \mathrm{C}$ for $1 \mathrm{~min}$ and at $95^{\circ} \mathrm{C}$ for $2 \mathrm{~min}$, respectively, to evaporate the solvent and to stabilize the resist layer as an adhesion layer. After adjusting the positions of the channel and heater substrates, we stuck them together at $65^{\circ} \mathrm{C}$ to allow tight contact 


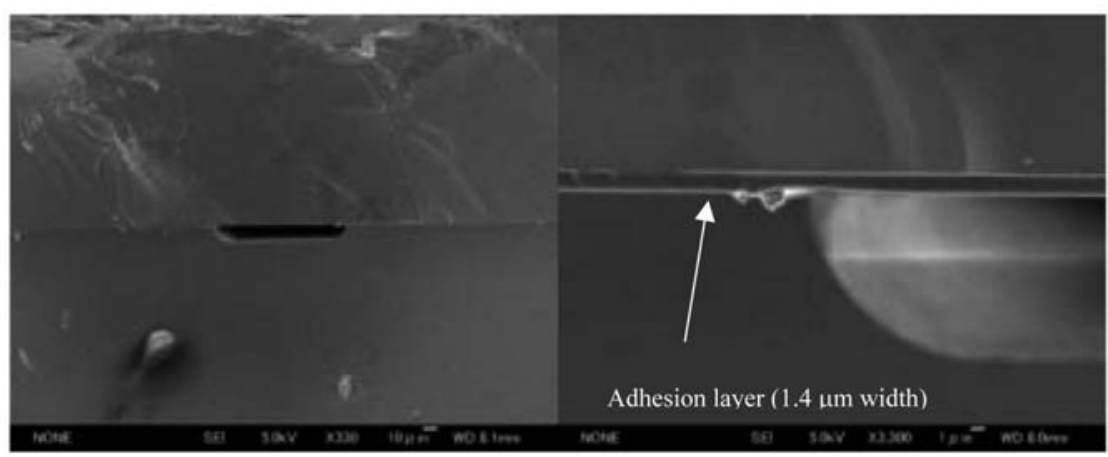

Fig. 3 SEM images of the cross section of the microchannel.

between the resist layer on the back side of the heater substrate and the channel substrate as shown in Fig. 1. It is worth noting that the photoresist layer becomes fluid at $65^{\circ} \mathrm{C}$ and this is very favorable for tight contact between the two substrates. When interference fringes were observed in the contacted substrates, the substrates were pressed at $95^{\circ} \mathrm{C}$ for a short time. The contacted substrates were then exposed to a $500 \mathrm{~W}$ mercury lamp for $180 \mathrm{~s}$, post-baked at $65^{\circ} \mathrm{C}$ for $1 \mathrm{~min}$, and soft-baked at $95^{\circ} \mathrm{C}$ for $1 \mathrm{~min}$ to allow cross-linking of the photoresist. Finally, the chip was hard-baked at $180^{\circ} \mathrm{C}$ for $10 \mathrm{~min}$.

\section{Solution flow system}

Two syringes (Hamilton, $100 \mu \mathrm{L}$ volume), one filled with $\mathrm{C}_{7} \mathrm{H}_{16}$ and one filled with FC-72, were equipped with a programmable dual syringe pump (Harvard Apparatus, PHD2000M). Each syringe was connected with the microchannnelmicroheater chip via a fused silica capillary tube (75 $\mu \mathrm{m}$ i.d. and $150 \mu \mathrm{m}$ o.d., GL Sciences Co. Ltd.) as shown schematically in Fig. 2. Connection between the tube and the inlet channel of the chip was made by using an epoxy resin. In the present experiments, $\mathrm{C}_{7} \mathrm{H}_{16}$ and $\mathrm{FC}-72$ were introduced separately into the chip with the same flow rate: $v=0.975 \mathrm{~cm} / \mathrm{s}$. The microchannel-microheater chip was connected with an electrochemical analyzer (ALS Co. Ltd., Model 701A) to apply a voltage $(V)$ to the microheater. Connection between the bonding pads and lead wires was made by a silver paste as an electroconductive adhesive, and the components were fixed with an epoxy resin.

\section{Raman microspectroscopy and 2D Raman mapping system}

Figure 2 includes an experimental setup of a confocal Raman microspectroscopy system. An $\mathrm{Ar}^{+}$laser beam (488 nm, Coherent, Innova 70) was used as an excitation light source for Raman scattering. The excitation light beam was introduced into an inverted optical microscope (Nikon, ECLIPSE E300) and irradiated to a sample solution in the microchip through an oil-immersion objective lens $(\times 100$, N.A. $=1.30)$. Ramanscattered light from a sample was passed through a pinhole (diameter $=100 \mu \mathrm{m})$ to ensure the confocal arrangement and, incident and Rayleigh-scattered light were removed by passing through two holographic notch filters for $488 \mathrm{~nm}$ laser light (Kaiser Optics). Raman-scattered light was then detected with a cooled CCD detector (223 K, Andor Tec.) equipped with a polychromator (1200 grooves $/ \mathrm{mm})$. The spatial resolutions along the lateral and vertical directions were 0.25 and $4.8 \mu \mathrm{m}$, respectively, and the spectral resolution was $2.0 \mathrm{~cm}^{-1}$. Exposure time was set at $120-300 \mathrm{~s}$ for Raman microspectroscopy. Raman intensity mapping (imaging) of a sample solution in the microchip was conducted by scanning the $488 \mathrm{~nm}$ laser beam (spot size $\sim 6 \mu \mathrm{m}$ ) in the area of $100 \times 80 \mu \mathrm{m}$. Laser scan steps along the $\mathrm{X}$ and $\mathrm{Y}$ directions were $6.25 \mu \mathrm{m}$ and $5.0 \mu \mathrm{m}$, respectively, and the exposure time was set at $10 \mathrm{~s}$ per step.

\section{Results and Discussion}

\section{Fabrication of glass microchannel-microheater chip}

The SEM images of the cross section of the fabricated chip are shown in Fig. 3. The images demonstrated that the microchannels with the depth of $10 \mu \mathrm{m}$ and width of $85.5 \mu \mathrm{m}$ could be fabricated in the present study. Furthermore, it was shown clearly that the glass channel and heater substrates were bonded successfully by a photoresist (SU-8 2002) with the thickness of the adhesion layer of $1.4 \mu \mathrm{m}$. The characteristic structure of the glass microchannel wall associated with isotropic wet etching can be seen in the images..25,26 This indicates that the present bonding method does not influence the structure of the fabricated microchannel even when a fluid resist material is used.

Conventionally, bonding between glass microchannels and cover substrates has been conducted by a thermal fusion technique, by which two tightly-pressed (i.e., weighted) glass substrates are heated above $450-650^{\circ} \mathrm{C}$ for $4-10$ h..$^{18,25,26}$ Alternatively, bonding can be done by using an aqueous HF solution (1 wt\%); two substrates inserted with an aqueous HF solution are pressed tightly together over $24 \mathrm{~h}$ at room temperature. $^{22}$ Although these direct bonding methods are employed commonly for fabrication of a glass microchip, the surface flatness of a glass substrate is a key factor for tight bonding; its throughput is not necessarily high, since surface roughness of a substrate(s) sometimes gives rise to formation of voids between the substrates. On the other hand, the present method that uses SU-8 2002 is very versatile; bonding can be made at low temperature $\left(<180^{\circ} \mathrm{C}\right)$ and in a short time $(<1 \mathrm{~h})$. Furthermore, the surface flatness/roughness of a glass substrate is not so important, since the fluid resist layer before light irradiation (see the Experimental section) can contact the two substrates tightly even for rough surfaces and successive thermal annealing of the resist layer leads to tight bonding between the substrates. Therefore, we think that the present method is superior to the other bonding methods mentioned above.

\section{Phase diagram of a n-heptane/perfluorohexane system}

Temperature $(T)$-dependent fluorous biphase behaviors have been reported for several systems, with typical examples being

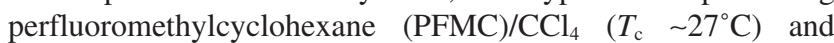
$\mathrm{PFMC} \mathrm{CHCl}_{3}\left(T_{\mathrm{c}} \sim 50^{\circ} \mathrm{C}\right) .{ }^{11}$ If one wants to study phase 


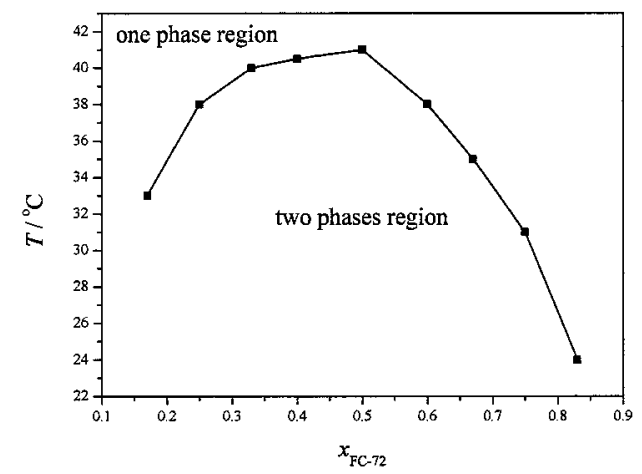

Fig. 4 Phase diagram of a $n$-heptane/perfluorohexane system. $x_{\mathrm{FC}-72}$ represents a volume fraction of $\mathrm{FC}-72$ in $\mathrm{C}_{7} \mathrm{H}_{16}$.
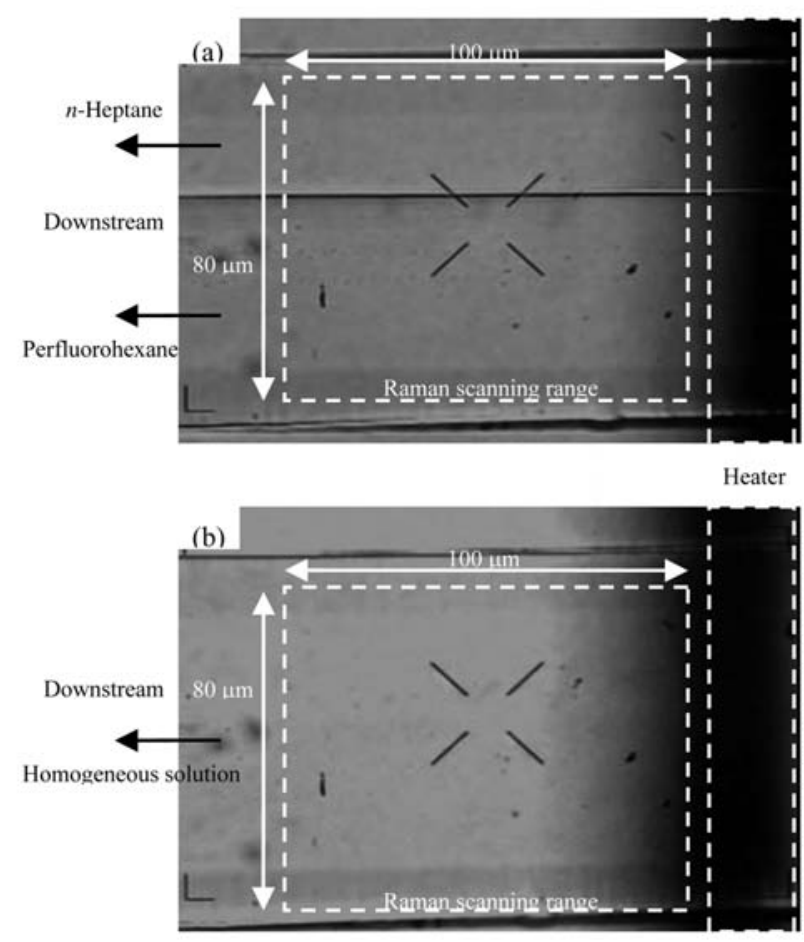

Heater

Fig. 5 Optical microscope images of solution flow behavior at $V=$ 0 (a) and $4.5 \mathrm{~V}$ (b). The cross bars in the images are a microscope gauge and possess no physical meaning. The dashed lines in the right-handed side in the images show the position of the microheater.

separation/mixing behaviors of a fluorous/organic solvent system in a microchannel-microheater chip, a system with a low or high $T_{\mathrm{c}}$ is not favorable experimentally. Therefore, we studied phase separation/mixing behaviors of several liquid/liquid systems and, we found that a $n$-heptane $\left(\mathrm{C}_{7} \mathrm{H}_{16}\right)$ /perfluorohexane (FC-72) system was suitable for the present purpose of the study. Figure 4 shows the phase diagram of a $\mathrm{C}_{7} \mathrm{H}_{16} / \mathrm{FC}-72$ system, which has been evaluated by observation of the phase separation behaviors in sample tubes by our naked eyes. The two liquids are separated at ambient temperature irrespective of the volume ratio, while those become miscible at a certain temperature-volume fraction combination, as shown in Fig. 4. At a $\mathrm{C}_{7} \mathrm{H}_{16} / \mathrm{FC}-72$ volume ratio of $1: 1$, the phase boundary vanished above $41^{\circ} \mathrm{C}$, which is very suitable for the experiments in a microchannel-microheater
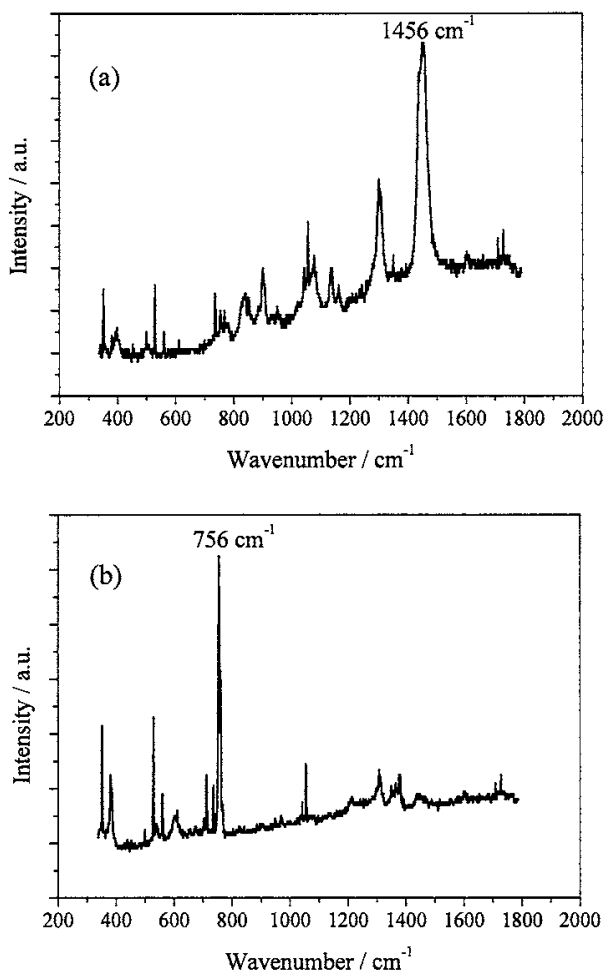

Fig. 6 Raman spectra of the $n$-heptane (a) and perfluorohexane (b) phases in the microchannel chip. Exposure time was set at $120 \mathrm{~s}$.

chip. Therefore, we conducted experiments at this volume ratio throughout the present study.

Phase behavior of $\mathrm{C}_{7} \mathrm{H}_{16} / \mathrm{FC}-72$ system in microchannel chip

An optical microscope image of a $\mathrm{C}_{7} \mathrm{H}_{16} / \mathrm{FC}-72$ system in the downstream side of the heater $\left(V=0,21^{\circ} \mathrm{C}\right)$ in a microchip is shown in Fig. 5a. Although we introduced the two liquids to the chip at the same flow rate $(v=0.975 \mathrm{~cm} / \mathrm{s})$, the liquids were not separated in the center of the channel width and the phase boundary was observed in the upper-side of the channel as seen in Fig. 5a, indicating that the flow width of the FC-72 phase was wider than that of the $\mathrm{C}_{7} \mathrm{H}_{16}$ phase. Although such flow characteristics were observed irrespective of the flow rate $v$ studied $(0.390-3.90 \mathrm{~cm} / \mathrm{s})$, one possible origin of the phenomena might be the difference in the actual flow rates of the two phases. Furthermore, the larger density of FC-72 (1.614 $\mathrm{g} / \mathrm{cm}^{3}$ at $\left.46^{\circ} \mathrm{C}\right)$ as compared to that of $\mathrm{C}_{7} \mathrm{H}_{16}\left(0.6637 \mathrm{~g} / \mathrm{cm}^{3}\right.$ at $45^{\circ} \mathrm{C}$ ) will also influence the flow characteristics. ${ }^{27}$ Since this is not the issue of the present study, we set $v=0.975 \mathrm{~cm} / \mathrm{s}$ throughout the study unless otherwise noted.

At $V>4.0 \mathrm{~V}$, the phase boundary seen in Fig. 5a became discernible. As a typical example, the results at $V=4.5 \mathrm{~V}$ are shown in Fig. 5b. Our rough calculations indicate that the temperature at the heater at $V=4.5 \mathrm{~V}$ is several tens of centigrade, which exceeds the phase-vanishing temperature of the system: $T_{\mathrm{c}}=41^{\circ} \mathrm{C} .{ }^{28,29}$ In order to obtain further detailed information about the phase vanishing behavior, we conducted Raman microspectroscopy studies of the system. Figure $6 \mathrm{a}$ shows the Raman spectrum of the $\mathrm{C}_{7} \mathrm{H}_{16}$ phase in the microchannel $(V=0)$. We observed a strong band at $1456 \mathrm{~cm}^{-1}$ characteristic to the $\mathrm{CH}_{3}$ antisymmetry deformation mode of $\mathrm{C}_{7} \mathrm{H}_{16} \cdot 30,31$ Similarly, the band characteristic of the bending vibration mode of $\mathrm{CF}_{2}$ was observed at $756 \mathrm{~cm}^{-1}$ in the $\mathrm{FC}-72$ phase, as shown in Fig. 6b. ${ }^{32}$ By monitoring such characteristic 


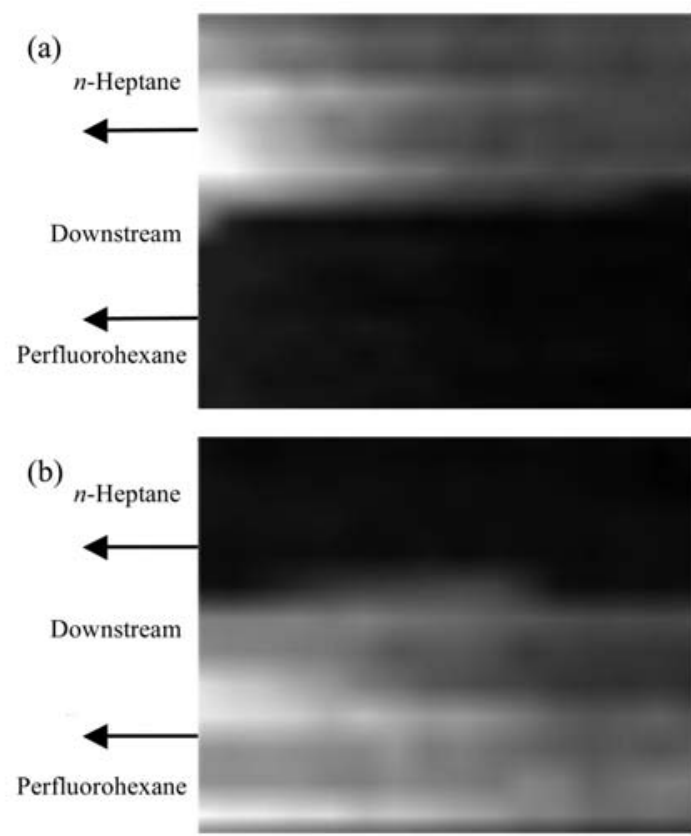

Fig. 7 Raman intensity images of an $\mathrm{FC}-72 / \mathrm{C}_{7} \mathrm{H}_{16}$ system in the microchannel chip monitored at 1456 (a) and $756 \mathrm{~cm}^{-1}$ (b) $(v=0.975$ $\mathrm{cm} / \mathrm{s}$ and $V=0 \mathrm{~V})$. Exposure time per a scan was set at $10 \mathrm{~s}$.

Raman bands of the two liquids, we conducted Raman intensity mapping of the solution system in the microchannel; the mapping area is shown in Fig. 5. The Raman intensity images monitored at $1456 \mathrm{~cm}^{-1}\left(\mathrm{C}_{7} \mathrm{H}_{16}\right.$, a) and $756 \mathrm{~cm}^{-1}(\mathrm{FC}-72, \mathrm{~b})$ at $V$ $=0 \mathrm{~V}$ are shown in Fig. 7 , where the bright areas represent those showing stronger Raman scattering intensity. In each image, the bright-dark boundary can be seen and its bright-dark image can be reversed by changing the monitoring peak from $1456 \mathrm{~cm}^{-1}$ (a) to $756 \mathrm{~cm}^{-1}$ (b). Therefore, the Raman scattering intensity mapping can image phase separation between $\mathrm{C}_{7} \mathrm{H}_{16}$ and FC-72 at $V=0 \mathrm{~V}$.

Then, we applied a voltage to the heater $(V=4.5 \mathrm{~V})$ to allow mixing of the two liquids; the results are shown in Fig. 8. Under the conditions, it is worth emphasizing that the phase boundary between the two liquids has vanished, similar to the results in Fig. 5b (see also Fig. 9). In the Raman intensity image, therefore, no bright-dark contrast should be observed, irrespective of the monitoring peak (1456 or $\left.756 \mathrm{~cm}^{-1}\right)$. Nevertheless, a bright region was observed in the upper or lower side of the channel, as demonstrated in Fig. 8a (monitored at $\left.1456 \mathrm{~cm}^{-1}\right)$ or $8 \mathrm{~b}\left(756 \mathrm{~cm}^{-1}\right)$, respectively. This indicates clearly that the two liquids are not mixed homogeneously at a molecular level. Although the spatial resolution of Raman intensity imaging is not necessarily high enough (laser spot $\sim 6$ $\mu \mathrm{m}$ and $6.25 \times 5.0 \mu \mathrm{m} / \mathrm{scan}$ ), the bright region in Fig. 8a corresponding to the $\mathrm{C}_{7} \mathrm{H}_{16}$-rich region extends to the FC-72 side in the channel along with solution flow to the downstream side. $^{33}$ When we monitor the FC-72 band at $756 \mathrm{~cm}^{-1}$, a reversed bright-dark image to that in Fig. 8a should be observed. However, we could not observe such an image in Fig. 8b. This suggests distribution of $\mathrm{C}_{7} \mathrm{H}_{16}$ to the $\mathrm{FC}-72$ phase along with solution flow to the downstream side in the channel. Such behaviors were observed irrespective of $V$ studied above $4.0 \mathrm{~V}$.

In order to investigate the observed phenomena at $V=4.5 \mathrm{~V}$ in more detail, we conducted Raman microspectroscopy measurements at several positions in the downstream of the

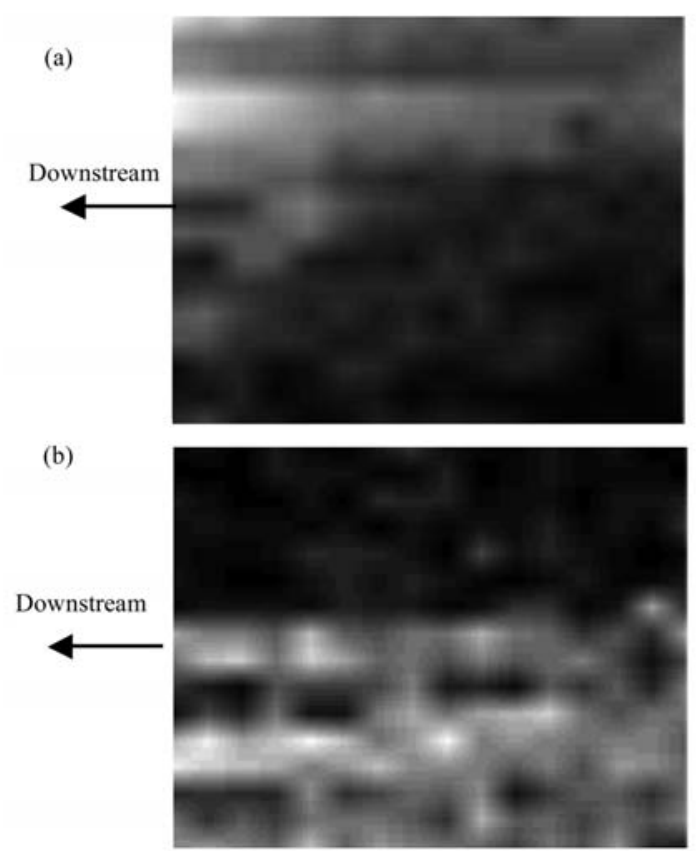

Fig. 8 Raman intensity images of an $\mathrm{FC}-72 / \mathrm{C}_{7} \mathrm{H}_{16}$ system in the microchannel chip monitored at 1456 (a) and $756 \mathrm{~cm}^{-1}$ (b) $(v=0.975$ $\mathrm{cm} / \mathrm{s}$ and $V=4.5 \mathrm{~V})$. Exposure time per scan was set at $10 \mathrm{~s}$.

microheater; the results are shown in Fig. 9. At $50 \mu \mathrm{m}$ in the downstream side of the heater in the central region of the channel width (position A), both 756 and $1456 \mathrm{~cm}^{-1}$ Raman bands contribute to the observed spectrum, indicating that the two liquids are mixed almost homogeneously. At position B (100 $\mu \mathrm{m}$ from the heater in the FC-72 phase), the Raman spectrum is characterized by the strong FC-72 band $\left(756 \mathrm{~cm}^{-1}\right)$ with a marginal contribution of the $\mathrm{C}_{7} \mathrm{H}_{16}$ band $\left(1456 \mathrm{~cm}^{-1}\right)$ to the spectrum. At position $\mathrm{C}(100 \mu \mathrm{m}$ from the heater in the $\mathrm{C}_{7} \mathrm{H}_{16}$ phase), on the other hand, the strong $\mathrm{C}_{7} \mathrm{H}_{16} 1456 \mathrm{~cm}^{-1}$ band was observed, while the band characteristic to FC-72 was almost invisible. As judged from the ratio of the integrated intensity of the $\mathrm{C}_{7} \mathrm{H}_{16}$ Raman band $\left(1400-1500 \mathrm{~cm}^{-1}\right)$ to that of the FC-72 band $\left(740-770 \mathrm{~cm}^{-1}\right)$ in Fig. 6, in practice, the contribution of $\mathrm{C}_{7} \mathrm{H}_{16}$ to the observed spectrum at position $\mathrm{C}$ was almost negligible, while that at position $\mathrm{B}$ was around $13 \%$. These results demonstrate distribution of $\mathrm{C}_{7} \mathrm{H}_{16}$ to the $\mathrm{FC}-72$ phase along with solution flow to the downstream side in the microchannel, which agrees very well with the results in Fig. 8. In the present case, heating of the FC-72/C7H16 system by the microheater should lead to more or less convection of the solution system, and this will induce mixing of the two solutions. However, although the heat expansion coefficient $(\alpha)$ of FC-72 $\left(1.9 \times 10^{-3}\right.$ at $\left.24-46^{\circ} \mathrm{C}\right)$ is larger than that of $\mathrm{C}_{7} \mathrm{H}_{16}$ $\left(1.2 \times 10^{-3}\right.$ at $\left.24-46^{\circ} \mathrm{C}\right),{ }^{27}$ the present results demonstrate that $\mathrm{C}_{7} \mathrm{H}_{16}$ distributes to the FC-72 phase, which is opposite to the result predicted from the $\alpha$ values. Therefore, we suppose that convection is not the main reason for the distribution behavior of $\mathrm{C}_{7} \mathrm{H}_{16}$. It is worth noting that solution flow in a microchannel is characterized by Hagen-Poiseulle flow and that solution mixing proceeds via molecular diffusion. ${ }^{34}$ Therefore, the present results can also be explained by the diffusion characteristics of $\mathrm{C}_{7} \mathrm{H}_{16}$ and/or FC-72 in the microchannel. It has been reported, furthermore, that a non-fluorous solute molecule interacts very weakly with a perfluorocarbon molecule(s) because of the strong electronegativity of the fluorine atom. ${ }^{35}$ Furthermore, since the viscosity $(\eta=0.7714 \mathrm{cP}$ 


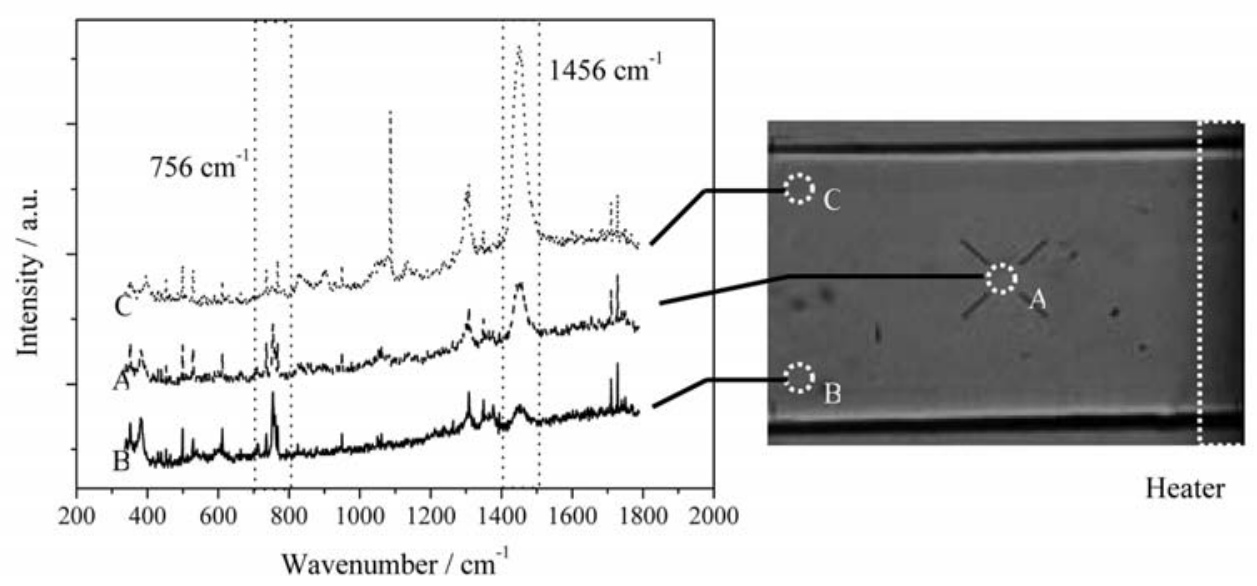

Fig. 9 Raman spectra measured in the microchannel at $v=0.975 \mathrm{~cm} / \mathrm{s}$ and $V=4.5 \mathrm{~V}$. Exposure time was set at $300 \mathrm{~s}$.

at $\left.23^{\circ} \mathrm{C}\right)$ and density $\left(\rho=1.614 \mathrm{~g} / \mathrm{cm}^{3}\right.$ at $\left.46^{\circ} \mathrm{C}\right)$ of $\mathrm{FC}-72$ are much higher than those of $\mathrm{C}_{7} \mathrm{H}_{16}\left(\eta=0.3967 \mathrm{cP}\right.$ at $25^{\circ} \mathrm{C}$ and $\rho=$ $0.6637 \mathrm{~g} / \mathrm{cm}^{3}$ at $\left.45^{\circ} \mathrm{C}\right),{ }^{36} \mathrm{C}_{7} \mathrm{H}_{16}$ is likely to distribute the $\mathrm{FC}-72$ phase, giving rise to the distribution behavior. Raman microspectroscopy and imaging experiments were successful in showing characteristic mixing behaviors of an $\mathrm{FC}-72 / \mathrm{C}_{7} \mathrm{H}_{16}$ solution system.

\section{Conclusions}

We fabricated glass microchannel $(85.5 \mu \mathrm{m}$ width and $10 \mu \mathrm{m}$ depth)-microheater (20 $\mu \mathrm{m}$ width) chips and applied the chips to $T$-dependent phase-vanishing behaviors of an $\mathrm{FC}-72 / \mathrm{C}_{7} \mathrm{H}_{16}$ system. At a solution flow rate of $0.975 \mathrm{~cm} / \mathrm{s}$ and $V=0 \mathrm{~V}$, the phase boundary between FC-72 and $\mathrm{C}_{7} \mathrm{H}_{16}$ could be seen in the microchannel and the two liquids run parallel to the downstream side in the channel, while the phase boundary was vanished at $V=4.5 \mathrm{~V}$. Raman microspectroscopy and Raman intensityimaging experiments on the system demonstrated, however, that the two liquids in the microchannel at $V=4.5 \mathrm{~V}$ were not mixed homogeneously at a molecular level. Furthermore, $\mathrm{C}_{7} \mathrm{H}_{16}$ was shown to be distributed to the FC-72 phase along with solution flow to the downstream side of the heater in the microchannel, probably due to the large differences in the solution density and viscosity between $\mathrm{C}_{7} \mathrm{H}_{16}$ and FC-72. Thus, the present Raman spectroscopic experiments were very successful in demonstrating phase-vanishing behaviors of a $\mathrm{C}_{7} \mathrm{H}_{16} / \mathrm{FC}-72$ system in a microchannel-microheater chip. It is worth noting that solution mixing in a bulk system is irreversible and its behavior cannot be observed steadily. In a microchannelmicroheater chip, on the other hand, $T$-dependent phasevanishing behaviors of a $\mathrm{C}_{7} \mathrm{H}_{16} / \mathrm{FC}-72$ system can be observed steadily and repeatedly under solution flow conditions; thus, simultaneous spectroscopic experiments can be done to elucidate the phase-vanishing processes. Spatially-resolved spectroscopy combined with a microchannel chip is very advantageous to study such solution mixing/separation processes and could be applied to various systems.

\section{Acknowledgements}

N. K. acknowledges Grants-in-Aid for Scientific Research from the Ministry of Education, Culture, Sports, Science and
Technology (MEXT) of the Japanese Government for the support of the research: 13863004 and 14050001 (Priority Research Area 417).

\section{References}

1. T. Saitoh, S. Ohkubo, and C. Matsubara, Chem. Lett., 1999, 151.

2. T. Saitoh, T. Ohyama, K. Takamura, T. Sakurai, T. Kaise, and C. Matsubara, Anal. Sci., 1997, 13, 1.

3. T. Saitoh, T. Ohyama, T. Sakurai, T. Kaise, K. Takamura, Y. Suzuki, and C. Matsubara, Talanta, 1998, 46, 541.

4. N. Kitamura, M. Yamada, S. Ishizaka, and K. Konno, Anal. Chem., 2005, 77, 6055.

5. I. T. Horváth, Acc. Chem. Res., 1998, 31, 641.

6. D. P. Curran, Angew. Chem., Int. Ed., 1998, 37, 1174.

7. I. Ryu, H. Matsubara, S. Yasuda, H. Nakamura, and D. P. Curran, J. Am. Chem. Soc., 2002, 124, 12946.

8. D. P. Curran, Synlett, 2001, 9, 1488.

9. E. de Wolf, G. van Koten, and B.-J. Deelman, Chem. Soc. Rev., 1999, 28, 37.

10. I. T. Horváth and J. Rábai, Science, 1994, 266, 72.

11. L. P. Barthel-Rosa and J. A. Gladysz, Coord. Chem. Rev., 1999, 190 - 192, 587.

12. K. Ueno, H.-B. Kim, and N. Kitamura, Anal. Chem., 2003, 75, 2086.

13. K. Ueno and N. Kitamura, Analyst, 2003, 128, 1401.

14. K. Ueno, F. Kitagawa, and N. Kitamura, Bull. Chem. Soc. Jpn., 2004, 77, 1331.

15. H.-B. Kim, K. Ueno, M. Chiba, O. Kogi, and N. Kitamura, Anal. Sci., 2000, 16, 871.

16. K. Ueno, H.-B. Kim, and N. Kitamura, Anal. Sci., 2003, 19, 391.

17. H. Hisamoto, T. Horiuchi, M. Tokeshi, A. Hibara, and T. Kitamori, Anal. Chem., 2001, 73, 1382.

18. M. Tokeshi, T. Minagawa, and T. Kitamori, Anal. Chem., 2000, 72, 1711.

19. N. Kitamura, Y. Hosoda, K. Ueno, and S. Iwata, Anal. Sci., 2004, 20, 783.

20. H. Hisamoto, T. Saito, M. Tokeshi, A. Hibara, and T. Kitamori, Chem. Commun., 2001, 2662.

21. A. Hibara, M. Tokeshi, K. Uchiyama, H. Hisamoto, and T. Kitamori, Anal. Sci., 2001, 17, 89.

22. K. Sun, A. Yamaguchi, Y. Ishida, S. Matsuo, and H. 
Misawa, Sens. Actuators, B, 2002, 84, 283.

23. J. Heo, K. J. Thomas, G. H. Seong, and R. M. Crooks, Anal. Chem., 2003, 75, 22.

24. N. Kitamura, Y. Hosoda, C. Iwasaki, K. Ueno, and H.-B. Kim, Langmuir, 2003, 19, 8484.

25. D. J. Harrison, K. Fluri, K. Seiler, Z. Fam, C. S. Effenhauser, and A. Manz, Science, 1993, 261, 895.

26. A. Daridon, V. Fascio, J. Lichtenberg, R. Wütrich, H. Langen, E. Verpoorte, and N. F. de Rooij, Fresenius J. Anal. Chem., 2001, 371, 261.

27. Determined in the present study by gravimetry.

28. On the bases of the dimensions of the fabricated microheater (see the Experimental section) and the resistivity of the metal $\left(2.35 \times 10^{-8}\right.$ or $12.9 \times 10^{-8} \Omega \mathrm{m}$ for $\mathrm{Au}$ or $\mathrm{Cr}$, respectively), the generated heat $(q)$ at the heater at $V=4.5 \mathrm{~V}$ was estimated to be $q=0.018 \mathrm{~J} \mathrm{~s}^{-1}$. Assuming the thermal conductivity $\left(k_{\text {glass }}=\sim 1 \mathrm{~W} \mathrm{~K}^{-1} \mathrm{~m}^{-1}\right.$ at room temperature) and the thickness of the glass substrate used $(d x=\sim 0.17 \mathrm{~mm})$, the $q$ value and the area of the heater $(A=$ $3 \times 10^{-8} \mathrm{~m}^{2}$ ) gave the solution temperature in the microchannel to be $\sim 100^{\circ} \mathrm{C}$ on the basis of Fourier's law. In the experiments, cooling of both solution and glass substrate takes place efficiently, so that the actual solution temperature should be much lower than $100^{\circ} \mathrm{C}$.

29. In the downstream side of the microheater, the mixed solution should be separated into two phases upon cooling. However, what we observed in the present experiments was an emulsion-like behavior: formation of FC-72 or $\mathrm{C}_{7} \mathrm{H}_{16}$ droplets in the $\mathrm{C}_{7} \mathrm{H}_{16}$ or $\mathrm{FC}-72$ phase, respectively. We anticipate that further optimization of the experimental conditions (channel dimension, channel surface treatment, and so on) will achieve separation of the solution into two phases.

30. D. A. Cates, H. L. Strauss, and R. G. Snyder, J. Phys. Chem., 1994, 98, 4482.

31. H. Hamaguchi and A. Hirakawa, "Raman Bunkou-Hou (in Japanese)", 1988, Gakkai Shuppan Center, Tokyo, 233.

32. J. L. Koenig and F. J. Boerio, J. Chem. Phys., 1969, 50, 2823.

33. Although the mosaic-like structure can be seen in Fig. 8 (particularly in Fig. 8b), this will not correspond to the microstructures of the liquid itself. Such structure is caused by the spatial resolution of the Raman imaging experiments; a Raman excitation laser beam with the diameter of $\sim 6 \mu \mathrm{m}$ is stepped 6.25 and $5.0 \mu \mathrm{m}$ along the $\mathrm{X}$ and $\mathrm{Y}$ directions, respectively.

34. R. E. Oosterbroek and A. van den Berg (ed.), "Lab-on-aChip", 2003, Elsevier, Amsterdam.

35. K. Kano, S. Yamamori, M. Yanagimoto, and S. Hashimoto, Chem. Lett., 1984, 379.

36. J. A. Riddick and W. B. Bunger, "Techniques of Chemistry: Organic Solvents", 3rd ed., 1970, Vol. II, WileyInterscience, New York. The $\eta$ value of $\mathrm{FC}-72$ at $25^{\circ} \mathrm{C}$ was determined in the present study by using an Ostwald viscometer. 